\title{
Study on the Path of Mutual Recognition of Credits between Universities on Both Sides of Taiwan Strait
}

\author{
Dongdong Weng \\ Quanzhou Normal University \\ Quanzhou, China
}

\author{
Xiaofang Wang* \\ Liming Vocational University archives \\ Quanzhou, China \\ weng28911985@163.com
}

\author{
Manping Weng \\ College of International Trade \\ Liming Vocational University \\ Quanzhou, China
}

\begin{abstract}
The issues of mutual recognition of credits, exchange of education, exchange of students, exchange of teachers and other issues on both sides of the Taiwan Straits have become the focus of experts and scholars and many students. This article will focus on the status quo and problems of the cooperation between colleges and universities in Fujian and Taiwan, explore the mechanism of mutual recognition of credits from the aspects of national policies and concrete implementation, build a talents innovation training platform in Fujian and Taiwan, and realize mutual recognition of teaching credits and links between courses in Fujian and Taiwan.
\end{abstract}

Keywords-Fujian and Taiwan higher education; Mutual recognition of credits; Link between courses; Exchange and cooperation

I. OVERVIEW AND Prospects OF TEACHING EXCHANGES AND COOPERATION BETWEEN COLLEGES AND UNIVERSITIES IN FUJIAN AND TAIWAN

\section{A. The Basic Situation of Teaching Exchange and} Cooperation Between Universities in Fujian and Taiwan

Under the background of the trend of internationalization of education and the increasingly perfect interactive development of vocational education between Fujian and Taiwan, Fujian shoulders the mission of exchanges and cooperation with Taiwan. It is of great practical significance to further strengthen cooperation in running schools between Fujian and Taiwan. Because Fujian and Taiwan are separated by only one river of water and are closely related to each other with similar cultures and unique geographical advantages, Fujian Province has fully implemented the important spirit of the Central Committee for the development of the cross-strait relations, guided the educational exchange and cooperation with Taiwan with the scientific concept of development, and played Fujian Province. The advantages of exchanges and cooperation with Taiwan are based on the principle of trialfirst-priority and strive for new breakthroughs and innovations. Taiwan's high-quality resources are relatively high-quality and its teaching staff is relatively strong. Taiwan's colleges and universities generally have the background of teachers in

\footnotetext{
Foundation Project:

1.Fujian Provincial Education Science "Thirteenth Five-Year Plan" 2017 Cross-Strait Vocational Education Special Research Project(FJJKHX17-077). 2..2018 Fujian Province Young and Middle-aged Teacher Education Research Project "I Offer Good Strategies for Building New Fujian" (United Front Work Project) (Key Funding Project) (JZ180019).

3.Quanzhou Normal University Student Innovation and Entrepreneurship Training Program Project Funding (Project No.: 201810399120).

*Corresponding author: Xiaofang Wang
}

European and American universities, and have a high academic level and strong practical ability. Fujian students' exchanges with Taiwan's schools will enhance individual learning ability and comprehensive quality from various aspects. . The cooperative education between Fujian and Taiwan transferred the outstanding resources of Taiwan to the Fujian region, opened up the horizon of mainland students and promoted exchanges and cooperation between Fujian and Taiwan.[1]

\section{B. Status Quo and Problems of Cooperation Between Colleges and Universities in Fujian and Taiwan}

Under the background of the trend of internationalization of education and the increasing development of interaction between Fujian and Taiwan, it is of great practical significance to promote the cooperation between universities in Fujian and Taiwan. Fujian province and Taiwan region are closely related to each other and have similar cultures. The unique geographical resources make it possible for the cooperation between universities in Fujian and Taiwan to have a good historical foundation for the cooperation between universities in Fujian and Taiwan. The Fujian Provincial Committee member of the CPPCC Education Committee most talked about how to use Fujian's relations. Taiwan's advantages in giving priority to the development of "education in Taiwan and Fujian" can be seen in the government's emphasis on educational exchanges and cooperation between Fujian and Taiwan.[2]

However, cooperation between colleges and universities in Fujian and Taiwan is still facing difficulties in mobilizing the participation of students in colleges and universities, improving the quality of education and sustainable development, and some colleges and universities in Taiwan do not recognize academic qualifications in China. There is a slight convergence of professional settings and internal management mechanisms are not yet available. Problems such as soundness and shortage of funds make the cooperation between universities and colleges in Fujian and Taiwan face difficulties. [3] 


\section{Future Prospects for Teaching Exchanges and Cooperation Between Fujian and Taiwan Universities}

In the future, the exchanges and cooperation in teaching between universities in Fujian and Taiwan will break through the traditional model of studying abroad, implement the $3+1$ model, study model, short-term experience model, and launch the "College School Enterprise" joint training talents program in Fujian and Taiwan. Fujian universities, Taiwan universities, Taiwan-funded enterprises, the three parties jointly develop professional personnel training programs, jointly formed teaching teams, joint development of professional, curriculum, teaching materials and other teaching resources database, joint training base construction, training for Taiwan-funded enterprises in the mainland A group of "reliable, useful" highquality applied talents.[4]

\section{The Significance of Credits Mutual Recognition And EDUCATION MATCHING IN THE COOPERATION OF COLLEGES AND UNIVERSITIES BETWEEN FUJIAN AND TAIWAN}

\section{A. Provide Human Resources Support for Taiwanese Companies}

Fujian is a province with a relatively large number of Taiwanese-owned companies. From the cost of labor, Taiwanese companies hope that all mid- and lower-tier employees of the company will be recruited at the investment sites. The cooperation between universities in Fujian and Taiwan and the mutual recognition of credits between Fujian and Taiwan universities make the students in Fujian and Taiwan more willing to learn from each other, so that they can train Taiwanese companies to meet the needs of their business development. This will be beneficial to the transformation and upgrading of Taiwanese enterprises and to Fujian. The improvement of soft power.[5]

\section{B. Improve the Level of College Education in Fujian and Improve the Employment Prospects of College Students in Fujian}

Taiwan's education has always focused on the practical application of talents, stressing fundamentals and advocating pragmatism. Various types of curriculum practice bases are built in schools, long-term cooperation practice bases are established outside the university and enterprises, and technical talents are cultivated. At the same time, extracurricular activities and community activities are emphasized, and students' communication and cooperation skills are cultivated so that students can be better To adapt to society, the employment prospects are even broader; at the same time, Taiwan's teachers are strong, mutual recognition of credits is realized, cooperation between universities in Taiwan and Taiwan is closer, and the level of education in colleges and universities in Fujian can be continuously improved.

\section{Enhance Taiwan Compatriots' Sense of Identity with the Same China}

Economically, when a large number of Taiwanese business enterprises are transferred to the mainland, while the enterprises are developing on the mainland, employees' awareness of the same China is also deepened, and so is education. If colleges and universities in Taiwan and Taiwan realize mutual recognition of credits and promote cross-Strait higher education cooperation and exchange, then the influence of Taiwan compatriots on the cognitive aspect of the same China must be far more profound than manufacturing. Because this sense of identity will have a greater impact on students and educators.

\section{HOW TO REALIZE MUTUAL RECOGNITION OF TEACHING CREDITS IN FUJIAN AND TAIWAN}

\section{A. Establish Related Certification Index System}

Gradually establish a national specialized agency responsible for formulating, verifying, coordinating and implementing the credit scoring system for related courses, comprehensively inspecting and studying the curriculum and credits settings of key and distinctive universities at home and abroad, building an internationalized curriculum structure, and coordinating the results of computational research. The "currency" can be circulated, operational rules can be formulated, steps can be taken in universities, trials can be carried out in batches, and dynamic monitoring can be implemented to ensure the internationalness of the index system, the timeliness of the update, and the relative fairness for different schools. We must increase the propaganda for the mutual recognition of credits while doing a good job of the existing work, so that more teachers and students can participate in the mutual recognition of credits and create a good atmosphere.

\section{B. Improve Credit Related Mutual Recognition Teaching Management System}

1) Improve student autonomy: Schools should allow the exchange students in Fujian and Taiwan to enjoy full autonomy and allow them to fully develop and improve themselves. Of course, the rights should allow students to learn and develop on their own, and should not be allowed to leave if the professional knowledge of the exchange students in Fujian-Taiwan is perfect. Since everyone is a different individual, with different understanding, different thinking, and different ideals, realizing the autonomy of exchange students can enable exchange students to achieve their own ideals and learn the knowledge and capabilities they really need.

2) Improve the school elective mechanism: The teacher of teaching management should do enough homework to familiarize himself with the basic conditions of teaching teachers, teaching contents and teaching time in the courses set up by the two schools in Fujian and Taiwan, and analyze the differences between the two parties so as to establish diversified courses and be attractive to exchange students. The curriculum will strive to improve the elective mechanism for the exchange of students who can effectively improve their literacy skills. Take seriously the deletion or increase of each course. After fully understanding the interest points of the 
students, the objective analysis of the relevant experts and professors is required to listen to suggestions and make changes to the curriculum.

\section{Set Up Credit Exchange and Mutual Recognition Sites}

1) Establishing "AC Angle" : Establish a special agency for exchange services between Fujian and Taiwan to allow teachers and students to communicate and communicate with each other and provide their own ideas and suggestions so that students with problems and difficulties can find school teachers in specific places to seek advice. . Let exchange students feel the care and attention of the school. At the same time, "Communication Corner" can also carry out face-to-face communication activities between exchange students and teachers on a regular basis, and through group exchanges, teachers and students can be closer together.

2) Establishing a Network Group Chat: Strengthen the network communication channels, use the Internet to create group chats such as WeChat group and qq group. When students and teachers don't have time to meet "Communication Corner", the group chat can quickly and conveniently integrate teaching management teachers and exchange students in a network group., Can communicate and communicate in a timely and timely manner. Exchange students have any questions. Management teachers can answer online promptly and provide timely management services for exchange student credits. Created a good communication environment and greatly improved the efficiency of the work.

3) Ensure the Equality of Communication: Regardless of whether it is the "Communication Corner" or the network group, we must ensure the equality of communication between teachers and students, and allow exchange students to enjoy the right of expression, advice, autonomy, etc. in the management of credits and mutual recognition teaching. Every communication must be conducted. We listened to the voice of the exchange students earnestly, respected the ideas of the exchange students, and created a sound and equal exchange atmosphere, thereby promoting the smooth progress of credit mutual recognition management and realizing the mutual recognition of credits between Fujian and Taiwan. [6]

\section{RELATED POLICY SUPPORT}

Relevant policies were introduced to promote cooperation and exchanges in teaching between universities in Fujian and Taiwan. First, the cross-strait government should provide policy guarantees on mutual recognition of credits. Both sides should see the good role of cooperative education in promoting cross-strait college education and economic development, and introduce relevant policies as early as possible to promote the mutual recognition of teaching credits between Fujian and Taiwan. This is also an important sign of the substantial progress made in the field of education in Fujian and Taiwan. Second, to constantly improve corporate related preferential policies, attract Taiwanese-funded enterprises to actively participate in cooperative education, achieve "triangle school enterprise" tripartite cooperation, and even can take compulsory measures to urge enterprises to participate in personnel training program. Of course, Fujian Province has always been committed to the cause of teaching cooperation between universities in Fujian and Taiwan. It has always been hoped that cross-strait students will learn from each other and continue to work hard to cultivate quality talents for the country. Fujian Province introduced Taiwan's IETET engineering and science and technology education certification, and was the first in the mainland to promulgate the "Fujian Provincial Association for Promoting Vocational Education Cooperation between Fujian and Taiwan", which all embody the achievements of Fujian-Taiwan education cooperation and exchange. It is hoped that the education circles on both sides of the Strait will further deepen cooperation and close interaction.[7].

\section{REFERENCES}

[1] M. Xu, H.H. Huang, and Y.P. Huang, "Analysis on the Policy of Exchange and Cooperation in Higher Vocational Education between Fujian and Taiwan," Fujian Tribune (Humanities and Social Sciences), vol. 11, pp. 151-156, 2011.

[2] G.Q. Xu, "Course Cohesion System: The Cornerstone of Modern Vocational Education System Construction," China Vocational and Technical Education, vol. 21, pp. 187-191, 2014.

[3] L. Sun, R.F. Yang, and W.P. Shi, "The Reality and Correctness of the Construction of the Linking System in the Chinese-Benjamin Curriculum," China Vocational and Technical Education, vol. 32 pp. 27$31+60,2016$.

[4] H.D. Dai, Research on the connection of the "Zhongbentong" course in vocational education, East China Normal University, 2016.

[5] Y.F. Liu and F.H. Zhou, "The convergence of middle and higher vocational courses: the demands from practice," Chinese Vocational and Technical Education,vol. 24, pp. 30-34, 2014.

[6] S.J. Chen and J. Mi, "Research on the Course Adaptation Path under Australian Qualification Framework (AQF)," China Vocational and Technical Education, vol. 14, pp. 60-65+69, 2017.

[7] H.X. Liu, "A Preliminary Exploration of Jointly Cultivating Talents in Vocational Colleges in Fujian and Taiwan," Education Review, vol. 05, pp. 110-112, 2009. 